\title{
Understanding Digital Events: process philosophy and causal autonomy
}

\author{
David Kreps \\ University of Salford \\ D.G.Kreps@salford.ac.uk
}

\author{
Frantz Rowe \\ LEMNA, Nantes University and \\ KTO, SKEMA Business School \\ Frantz.Rowe@univ-nantes.fr
}

\author{
Jessica Muirhead \\ Wrexham Glyndŵr University \\ Jessica.Muirhead@glyndwr.ac.uk
}

\begin{abstract}
This paper argues that the ubiquitous digital networks in which we are increasingly becoming immersed present a threat to our ability to exercise free will. Using process philosophy, and expanding upon understandings of causal autonomy, the paper outlines a thematic analysis of diary studies and interviews gathered in a project exploring the nature of digital experience. It concludes that without mindfulness in both the use and design of digital devices and services we run the risk of allowing such services to direct our daily lives in ways over which we are increasingly losing control.
\end{abstract}

\section{Introduction}

The deployment of digital and social media technologies is increasingly being understood as an ethical issue [34] with negative intended [14] and negative unintended consequences [39, 41]. In this paper we argue that immersion in ubiquitous networks of digital devices that take part in co-directing our lives risks overwhelming the director within us. To counter this risk IT mindfulness $[22,36,42,7,38]$ is needed, and should be factored into design and use.

We stress that we are not saying that the technology itself is somehow 'bad'. Bad design is responsible for many of the issues that have been raised. However, with the number of algorithms and the increasing involvement of artificial intelligence in the running of these technologies, designers are no longer necessarily always in control themselves: algorithms can have unintended consequences. With the digital, users add content and interact sometimes in ways unanticipated by designers. Mitigating risks, therefore, requires conscious effort, both by users, and by designers. However, and crucially, users may be overwhelmed by the digital world they inhabit, as they try to coordinate multiple independently designed digital devices while they do not and cannot have the competencies to do so, as the world of the digital continues to innovate at break-neck speed. But even if everything was good, and all digital and social media technologies were designed with the utmost care, we argue that there is still too much of it: that it is possible to be overwhelmed by too much of a good thing!

We argue that digital events may be happening continuously in a way that we must better understand if we are to investigate and possibly mitigate negative consequences. We first provide a philosophical position on the nature of an 'event,' and then consider what may be described as a 'digital event.' In the next section we describe a continuum between polar positions on how human actors and technology interact [24]. We then outline our methodology and provide examples from the empirical data and a thematic analysis that supports our claims. ${ }^{1}$ In the last section we seek to propose what might be done to counter the problems we have identified.

\section{Lenses for understanding digital events}

In this section, we lay out the features of the series of lenses, through which we examine the nature of an 'event,' and then what we understand as a 'digital event.' Firstly, our analysis is based in the process philosophy of Henri Bergson and Alfred North Whitehead, and their focus upon duration, relation and multiplicity - upon events - rather than upon fixed things. In addition to this, however, we also make use of the image of the 'elephant and rider' in the moral psychology writings of Jonathan Haidt [13], and the 'philosophy of the flesh' introduced by Lakoff and Johnson [21], as ways of understanding Bergson and Whitehead's concerns in the language of contemporary psychology and philosophy.

These lenses for understanding are then further refined, for the IS community, by relating insights from process philosophy to the causal autonomy dimension which stresses the relative role of human actors and technology in their interaction [24]. We

\footnotetext{
${ }^{1}$ This study was funded as part of a British Academy Mid-Career Fellowship awarded for the duration of 2018 to David Kreps. http://www.concrescence.org.uk/
} 
outline a continuum between pure Human Sovereignty (HS) and complete Technological Autonomy (TA), with the understandings of sociomateriality somewhere in the middle, and the notion of 'infomateriality' [18] closer to the Technological Autonomy end. We propose some refinements to this continuum supported by the empirical data from the project. We also make use of Mark Coeckelbergh's framing of the digital as a space in which technology is increasingly responsible for some co-direction of our lives [10].

\subsection{Process philosophy}

The two 'fathers' of process philosophy were French philosopher Henri Bergson, and British mathematician and philosopher Alfred North Whitehead. They propose 'event-ontologies' $[23$, p. 232], in contrast to the 'thing-ontology' that is the prevailing world view; i.e. they contend that 'things' may be reduced, ultimately, to 'events', in contrast to the more positivistic approach which seeks not only to reduce, but to eliminate 'events' in favour of 'things.' Although modern physics does not "appear to entail" such an event ontology, it is certainly "consistent" with it [23, p. 234].

Both philosophers seek to re-integrate consciousness and personal experience into a scientific reality they regard as having banished it. Whilst they both try thus to bridge the gap between subject and object, Bergson errs somewhat on the side of the subjective, and Whitehead somewhat on the side of the objective. Bergson is thus the braver and more radical philosopher, focussing on the facility of free will and its place within the universe.

2.1.1 Bergson. Of all Bergson's core ideas, the durée reélle may perhaps be regarded as his primary insight: an understanding of the nature of time published as his first book, Time and Free Will [1]. For Bergson the will is intimately linked both to consciousness and to duration. Free will - the ability to choose between different possible courses of action is, for Bergson, an ontological quality of time understood as consciously experienced duration in which we play a part - the durée reélle. In mechanistic physics, Bergson argues, by contrast, time is a property of a deterministic causal closure, whereby all macro phenomena result inescapably from micro phenomena, and we - the observers - are absent, epiphenomenal, impotent. This mechanistic universe could run from beginning to end in 3 seconds or 3 trillion years: it would make no difference. Bergson's durée reélle, however, hinges upon 'indetermination': the moments of possibility within consciously experienced duration when human choices can be made, and the universe take a different course. This durational universe is making itself up as it goes along, a 'creative evolution,' (the title of Bergson's most famous book. [2])

Mechanistic time, crucially, like all equations, can run forward or backward. Yet the nature of succession in consciousness flows only forward. As Bergson insists, this durational "succession exists, I am conscious of it; it is a fact" [2, p. 368] - and it is when free will is exercised. Our memory assists us with weighing up different potential routes, and then we choose, and action unfolds. From this, Bergson goes on to elaborate a universe on the model of consciousness, acknowledging that, for it to exist at all, it must have been implicit from the very beginning $[3,35]$.

2.1.2 Whitehead. Whitehead's cosmology and metaphysics include his four-dimensional geometry in which the process of concrescence - or gradual coming to be and passing - of Actual Occasions into Objective Data is described, and an organic philosophy that results from this process-relational ontology. For Whitehead, in the simplest terms, "the future does not exist" [26, p. 4]. Whitehead represents "an effort to think clearly and deeply about the obvious truth that our world and our lives are dynamic, interrelated processes, and to challenge the apparently obvious, but fundamentally mistaken, idea that the world (including ourselves) is made of things that exist independently of such relationships" [26, p. 8]. Once we have grasped this shift in perspective, it becomes clearer that the building blocks of reality are no longer fixed things but must be recognised as sets of interrelated events.

Whitehead's geometry constitutes a fourth - and better - description of reality than the three competing views in quantum mechanics: (i) that reality is particulate, with wave-like properties, (ii) that reality is wave-like, with particulate properties, and (iii) that nature, so determined by the means by which we study it, e.g. giving us position but not momentum if studied one way, or momentum but not position if studied another, is so uncertain that it is simply not "capable of fundamental characterisation at all" $[11, \mathrm{p}$. ix $]$. The fourth approach is to focus on becoming, rather than being, as Whitehead does in his philosophy of events, created at the same time that Einstein (i), Schrödinger (ii) and Bohr (iii) were creating their own views.

In Whitehead's organic philosophy "everything experiences" [33, p. 21]. In his view, "Biology is the study of the larger organisms; whereas physics is the study of the smaller organisms" [43, p. vi]. He thus refuses to restrict sentience to the higher mammals and insists that "every singular actuality" as it takes part in the concrescence of new events "must be related to ... a world of antecedent actualities. In this regard, the actuality is a subject whose object is a world of antecedent subjects" [25, pp. 11-12]. Such 
panpsychism deems "All objects, or systems of objects, [to] possess a singular inner experience of the world around them" [33, p. 16], a world in which "experience is impossible without an experiencer" [35, p. 23] and "experiential phenomena cannot be emergent from wholly non-experiential phenomena" [35, p. 21]: a world built, in other words, on a model of consciousness.

2.1.3 A unified process approach. For Bergson, the idea of a homogeneous and measurable time is an artificial concept, a geometry for determinism. Duration reinserts human experience into the universe. Whitehead addresses this by focussing upon the notion of the 'event' as a core unit of existence, in a 'structure of events' [44, p. 52]. He speaks of "a duration" as "a concrete slab of nature limited by simultaneity which is an essential factor disclosed in sense-awareness" [44, p. 53]. This 'duration' is something that is both our subjective experience of an event: a non-physical consciousness of what is unfolding; and what the physico-chemical sciences would say about the materiality engaged in the event: the movement of molecules, dynamics of forces, mass, volume and charge of the particles engaged in what is unfolding. The accent is upon movement: reality is thus describable only in terms of 'periods' during which conscious and physical interactions and shifts occur. Hence the term, 'process' philosophy.

The main difference between Bergson and Whitehead is that for the former the universe is qualitative and durational before it manifests itself as physicality, albeit that without physicality it does not exist. Now, as Whitehead said, "There is very little large-scale understanding, even among mathematicians. There are snippets of understanding, and there are snippets of connections between these snippets" [45, p. 46]. This paper offers new snippets of connections between snippets of understanding.

The key point arising from this philosophical synthesis is that the fundamental fact of conscious free will is inherent in the very fabric of the universe. This is a universe not built upon (i) particles, (ii) waves, (iii) neither, nor merely upon (iv) becoming. It is a universe built upon the model of consciousness, whereby choices are made and unfold through the process of becoming. This has profound implications for all disciplines.

This assertion is in keeping with the notion that it is in 'events', in becoming, that reality is truly to be found, rather than in things; that an event-ontology that entails panpsychism rings truer than the positivistic thing-ontology that underlies (and arguably undermines) so much of contemporary scientific thought [31]. What we perceive, moreover, as objects, are not "senseless, valueless, purposeless" [43, p. 17], but allow for affordances [17]. The physical, and conceptual (mental) feelings always go together, forming two poles within every entity, and everything is related to everything else.

2.1.4 Contemporary views. More contemporary writers than Bergson and Whitehead provide insights that are strikingly in keeping with process philosophy. According to Haidt [13], there are two kinds of cognition: "the rider (controlled processes, including 'reasoning-why') and the elephant (automatic processes, including emotion, intuition, and all forms of 'seeing-that')." Automatic processes "run the human mind, just as they have been running animal minds for 500 million years, so they're very good at what they do, like software that has been improved through thousands of product cycles." The other character in this dyad, "the rider, (language-based reasoning) evolved because it did something useful for the elephant." The rider allows us to look "into the future (because we can examine alternative scenarios in our heads) and therefore it can help the elephant make better decisions in the present" [13, pp. 53-54]. Here is Bergson's mechanism of choice in the moments when our consciousness intervenes in the flow of the durée réelle. It is the durational time-scale gap where (as Hirai [17] shows us) our ability to compare possible routes into the future and choose one literally constitutes our consciousness.

Lakoff and Johnson [21] describe this picture as a Subject and a range of Selves. "The Subject is the locus of consciousness, subjective experience, reason, will." In addition to this, "there is at least one Self and possibly more. The Selves consist of everything else about us - our bodies, our social roles, our histories" [21, p. 268]. Crucially, "The Subject is that aspect of a person that is the experiencing consciousness and the locus of reason, will, and judgement, which, by its nature, exists only in the present" [21, p. 269 emphasis in original] - this is clearly the experiencer of durée and exerciser of free will in Bergson's worldview.

Armed with these philosophical and psychological insights, we will now consider 'digital events'. We will use the metaphor of the elephant and rider not just in the sense meant by Haidt, but recalling the process philosophy by which the rider - as Subject and as consciousness - expresses the free will that helps constitute not only ourselves but a universe understood upon the model of consciousness, in which such Human Sovereignty is a moral, ethical, and political good. This model of the universe, as we shall see, is threatened by the digital world we increasingly inhabit.

2.2 Human Sovereignty and Technological Autonomy 
When studying cause-effects relationships between human actors and IT, a spectrum of positions can be considered between two poles [24]. At one pole, "Human Sovereignty" (HS), in fact a traditional position, considers that "technology is an inanimate product of intentional human action and therefore only people can be viewed as causal" [24, p. 1269]. Technology cannot take initiatives: it strictly follows a plan designed by human actors. This typically applies to situations where decisions are the object of human deliberation and are supported by tools providing some information related to the task but not acting.

At the other end of the spectrum, with "Technology Autonomy" (TA) Markus and Rowe consider that "technology can affect humans and operate with limited human intervention" [24, p. 1270]. Some autonomous systems such as automated transportation systems do not only operate without drivers but are regulated in highly automated ways. They are copiloted both by some artificial intelligence and by humans. However, these directive decision devices are designed to actively prevent human intervention into their operation [37]. Human surveillance may be necessary, but intervention remains very infrequent and considered only when facing a crisis situation (e.g. safety). When relying on deep learning, they can take a life of their own (we do not need to grant them with consciousness for that i.e. to qualify them as strong Artificial Intelligence) [20].

In between these two poles representing concrete and actual situations - inanimate products that simply inform and cannot act, and systems that can have a life of their own - there is a spectrum of situations. First, operations can be run by humans with decision aids for handling simple to complex tasks that may interact or not. By complex tasks we mean tasks that can encounter a considerable diversity of situations and actors so that their outcomes are very context dependent and cannot be predicted with great precision.

In such cases technology can take some initiatives and decide within some limits what is to be done, beyond which humans have to intervene. We may call these semi-autonomous systems. Such situations are typical of our digital world and the web 3.0 - the newly mangled internet of things and people [19, 28]. In these situations, the objective is to regulate some function, or maintenance (of industry, homes, cities, human health conditions). Semi-autonomous systems can be placed on a continuum between the abovementioned poles of human sovereignty aka non autonomous systems and technology autonomy aka fully autonomous systems. In the case of autonomous cars, one distinguishes level 1: one or a set of functions (e.g. cruise control) being automated with no interactions among them; level 2: at least two functions interacting automatically; level 3: temporarily the car is taking full control, but in complex situations the driver is notified to regain control; level 4: no driver is required, aka this is an autonomous system [15]. Between level 0 (HS) and level 4 (TA), three types of digital events can thus be experienced by the driver. Co-piloting or auto-pilot does not demand nor reflect the same physical engagement with the car and attention to the dashboard as we move from level 1 to level 3.

In the case of autonomous cars, Bruckes et al. assert that "situational normality of using autonomous systems increases the perceived ease of use." [5]. However, the normality of the situation as perceived by users is highly debatable and does not only depend on the technology and its embeddedness in a (level 4) autonomous product but also on the environmental context which may include different people and stakeholders and connected technologies. The presence of other people and networked devices may considerably affect risk perception, capacity to understand and act, and reinforce a feeling of being overwhelmed - not so much by quantity as by complexity. [27].

Digital transformation of our lives and societies goes beyond moving towards higher degrees of technology autonomy in the sense described above which focuses on action. Social media and robots once introduced in our homes shape how our individual times and actions unfold in our social life and existence. Thus, they may give it a different meaning and reflect an ontological shift from a causal mechanism such as automation levels supporting action (described above) to how we constitutively ascribe meaning to our world and existence [24]. Social media puts us frontstage "acting in a play that is not only written by me but also by others and by the technologies and media I use" [10, p. 35]. We do not only set the targets for driving somewhere, for maintaining our homes at certain temperatures and refilling our refrigerators, the digital tools we use also create other unexpected interactions that shape our lives in what we do (or continue to do) and don't, and the sequence in which we do things and ascribe meaning to what we ordinarily do such as getting up in the morning. "Technology is not just something we use in our performances [...] and not even just a potential co-actor (actant), but also an author and director of these performances" [10, p. 27]. To what extent is it an author of our lives? To what extent does it set certain goals indirectly by switching our attention or directly by certain impositions?

2.2.1 Digital events as co-directors. In Whitehead's philosophy we can see that an 'event' is 
unbounded; Whitehead's temporal geometry shows how for any event, there is a beginning which involves everything around it, a middle which is always a process, and an end which involves passing into a past where it becomes the stuff from which other events are made. Crucially, the present is where subjectivity resides, the past being the objects from which it is made up: a panpsychic level of consciousness permeates all interrelations, and all events contain and are contained within other events. The boundaries between events thus become almost indistinguishable in a field of continuously unfolding, interpenetrative and interoperable multiplicity. Focussing upon the discrete reveals only one perspective; acknowledging the multiple provides a glimpse of the complexity and contingency of the real.

We see that Digital Events are also unbounded through their interactions, in this manner. Along the continuum from Human Sovereignty to Technological Autonomy, we have therefore identified three distinct gradations, to which we have given a nomenclature of DE1, DE2, and DE3, denoting three kinds of Digital Events along that continuum, whilst acknowledging that finer gradations might also be delineated, through further examination.

Table 1 Typology of Digital Events

\begin{tabular}{|l|l|}
\hline $\begin{array}{l}\text { Digital } \\
\text { Event }\end{array}$ & Definition \\
\hline DE0 & Products that simply inform and cannot act \\
\hline DE1 & $\begin{array}{l}\text { One or more automated functions with no } \\
\text { interactions among them }\end{array}$ \\
\hline DE2 & $\begin{array}{l}\text { Minimum two functions interacting } \\
\text { automatically }\end{array}$ \\
\hline DE3 & $\begin{array}{l}\text { The system taking full control temporarily } \\
\text { though in complex situations the human is } \\
\text { notified to regain full control }\end{array}$ \\
\hline DE4 & Autonomous system. No human required \\
\hline
\end{tabular}

Digital Events of type 1 (DE1) - using third-party applications on the platform devices in our hands that source assets and processing from remote servers - are commonplace and not the focus of this paper. DE2 where two or more services or functions are interacting with each other in the background - have also become so commonplace we hardly notice them. DE3 are typical of the Web 3.0 A.I.-powered future we are being invited to embrace, and which in this paper we are concerned may require risk-mitigating design and/or use focus. As with events in Whitehead's ontology, the boundaries between these types of digital events are indistinct, and each contain and are contained by other digital events.

Thus, in contemporary highly technological society, we contend, there are unbounded digital events that are increasingly immersive and ubiquitous - closer to DE3 than to DE1 - whose obligations upon us seem to weigh as heavily as those related to our peers: where the digital tools we use become co-directors of our lives as powerfully as other people - and indeed constitutively causal in the development of the Selves surrounding the Subject who is experiencing; our becoming ourselves is co-constituted not only by those around us, but by these digital events.

Nor are they always benign. Already in our experience of what seem like DE2 Events, such as engaging with social media on our smartphones, elements of what defines DE3 events are at play. Nir Eyal [12] describes how "The technologies we use have turned into compulsions, if not full-fledged addictions. It's the impulse to check a message notification. It's the pull to visit YouTube, Facebook, or Twitter for just a few minutes, only to find yourself still tapping and scrolling an hour later. It's the urge you likely feel throughout the day, but hardly notice" [12, p. 1]. The 'hook' model [12, p. 4] he describes "brings together an understanding of user behaviour and a carefully considered set of interactions that entice people into using a product or service more and more. If you can connect a user's need (unconscious or otherwise) with your service frequently enough ... the user will begin to form a habit of using it." [6 p.67]. By repeatedly looping through the steps, "the user begins to associate the behaviour with their own internal motivations and emotions" [12, p4] These habits are self-reinforcing through reward and admonishments.

Such 'hooks,' in the context of our philosophical lenses, can be read as a case of technologies driving the elephant, of the system of elephant-computer interaction taking temporary full control, overwhelming what might be the more considered conscious and durational - intentions of the rider. This is nearer to DE3 than to DE2. All too often it is the deliberate intent of the designer to appeal directly to the elephant, sidestepping the rider through carefully integrated psychological tricks [32]. There is a growing amount of literature on the ways in which social networks, in particular, undertake this kind of trickery [e.g. 40].

When we say, then, when asked, that we are acquiescent to the tricks of digital companies like Facebook, that we understand they use our data because they are a business, is our surrender not also a surrendering of an awareness of the risks involved? If we are, as Haidt and Lakoff and Johnson show, all too often guided rather by the elephant than the rider, when we are immersed in DE3 type networks that are geared toward driving the elephant, just who is in control? Is our consciousness making choices, or are the automatic processes of our bodies being led by automated hooks? 
There is a tangible danger of our ability to choose being overwhelmed when too many DE3s are present.

This constitutes a modification to Coeckelbergh's co-direction: it suggests that in the right (or wrong) circumstances, we are no longer co-directing our own lives, but subject to the hooks, tricks, and controls of the ubiquitous digital environments in which we are immersed: that our lives are being directed. While this may be reasonable in certain circumstances, more and more digital events are occurring beyond DE3 type events at the Technological Autonomy end of the spectrum. If true, this leads us to refine our sociotechnical perspectives. In particular, not only the human-centred human sovereignty ideal may have become a modern demagogical myth, but the academic perspective on sociomateriality may soon be outdated. First, at the heart of this latter perspective is the idea that the social and the material cannot be distinguished fundamentally [29]. However, sociomateriality does not sufficiently and precisely reflect the nature of the tools that have become constitutive of the physical context in which we live. This a world which we have made and are rapidly remaking, through a digital transformation process which represents an anthropogenic shift. We argue only the notion of the 'infomaterial' truly acknowledges the key element of human meaning already inherent within 'information' $[8,18]$ as causal [24]. Second, based on process philosophy we argue that, unlike sociomateriality, infomateriality focuses more upon the physical and the durational, and less upon ephemeral social 'structures.'

\section{Methodology}

With a tight timescale of only a few months, this study was more a proof-of-concept pilot of what and how people experience the physical and durational in their digital world and where digital events fit in the HS $\rightarrow$ TA continuum than a full study, and was focused on obtaining quality in-depth information. We were conscious that when seeking information on digital experience there are a number of 'digital divides' to consider, including in the younger generation, for whom the digital world is something they have grown up with; education and family income remain key to access beyond the cheapest smartphones with limited data allowance. If this younger generation, we reasoned, were finding new technologies encroaching upon their conscious ability to direct their own lives, then surely other, older generations, would be finding this even more so. We recruited, therefore, a small cohort of participants, aged 18-25, from both IT and non-IT backgrounds, aiming to garner responses representing a spectrum from digital novice to in-depth knowledge and experience of the digital world. Diary studies were undertaken with a total of 12 participants. Diaries lasted typically for 4-6 weeks, with 2-3 entries per week, and 2 interviews were then undertaken.

Thus, although our participants were not a statistically representative cohort, we were able to infer, from our knowledge of the participants, that a reasonably wide range of backgrounds, income brackets, and educational levels were represented, as well as a reasonable gender balance. Interviews were recorded, typed by an independent transcriber, and then imported into NVivo. An interview plan was drawn up in advance, dividing each simply into three parts: (i) follow-on questions arising from their diary entries, (ii) privacy issues around online services in general, (iii) opinions on personal online digital experience.

\section{Findings}

Our analysis made use of a priori themes: the framework on digital events described in section 2, with Eyal's notion of the 'hook,' Haidt's metaphor of elephant and rider, the HS $\rightarrow$ TA spectrum, and the process philosophy of Bergson and Whitehead. With all the diary entries and interviews entered into NVivo, we employed search terms with NVivo synonyms and coded the data using thematic analysis [4]. Our coding was thus not an inductive process. Through this analysis we hope to approach a philosophical explanation, not yet a theory, that speaks to the IS community.

\subsection{Single and multiple events}

Although participants were asked to describe in their diary entries their experience of discrete digital events on a single digital device, in a finding redolent of the unboundedness of digital events, and the richness and complexity of people's digital interactions, we found that the 75 diary entries in fact describe multiple digital events across a range of applications on their devices. Not one of the entries describe single discrete digital events. Some $68 \%$ of entries describe several discrete digital events taking place at the same time within the one device. A third category - the other $32 \%$ - describe several non-distinct or combined simultaneous digital events involving multiple applications. For us this means that the digital event world - especially of this latter group - is more multiple and continuous than made of single discrete and unique events, and this is very redolent of Whitehead's process-relational vision of events in general. 


\subsection{From directing, to co-direction to being directed?}

In our thematic analysis, we found that the data demonstrates all three types of digital events. In Table 2 we present example diary entries for each.

Table 2 Examples of Digital Event Types

\begin{tabular}{|c|c|}
\hline $\begin{array}{l}\text { Digital } \\
\text { Event }\end{array}$ & Example [participant code] \\
\hline DE1 & $\begin{array}{l}\text { I'm using my iPhone to listen to music - } \\
\text { Spotify. I generally listen to the "Daily } \\
\text { Mix" playlists that are personalised for me } \\
\text { on my previous usage. Extremely good and } \\
\text { the playlists generally get better the longer } \\
\text { you use Spotify for. [A3-26] }\end{array}$ \\
\hline DE2 & $\begin{array}{l}\text { I enjoy the simplicity of being able to login } \\
\text { with one account and have access to all of } \\
\text { these different tools simply by being logged } \\
\text { into Chrome. [A3-26] }\end{array}$ \\
\hline DE3 & $\begin{array}{l}\text { I feel like we probably take all these } \\
\text { services for granted like Gmail, Yahoo or } \\
\text { whoever it is nowadays and we think, 'oh, } \\
\text { we can trust them, they can take decisions } \\
\text { for us and will make sure that we receive } \\
\text { the right emails in our inbox and everything } \\
\text { that is spam will go into the junk folder'. I } \\
\text { believe maybe they should do it from time } \\
\text { to time, like an update of settings or } \\
\text { something... Two weeks ago I switched my } \\
\text { bank and I was receiving the emails in my } \\
\text { inbox for the first few days and then I was } \\
\text { expecting a status on the switch process and } \\
\text { I didn't receive anything. I had to ring them } \\
\text { and they said everything is fine and I don't } \\
\text { usually check my spam folder and I } \\
\text { checked it and all the emails after that went } \\
\text { to my junk. I missed out on something } \\
\text { because there was a direct debit that was } \\
\text { supposed to come through and because I } \\
\text { didn't receive the email on time I missed } \\
\text { out on that so I had to pay a bit over... [A3- } \\
16 \text { ] }\end{array}$ \\
\hline
\end{tabular}

In the DE1 example there is a simple engagement with a single function on the smartphone - Spotify that delivers music from that service. In the DE2 example multiple services are used together to provide benefits to the user, with a consistent experience of all tools being provided through a single login. In the DE3 example, however, the participant is very clear that they want to retain autonomy and control, rather than give it over to a third-party email provider. The administration process for a new banking customer is highly or at least partly automated. At the stage referred to in this quote, A3-16, the customer, is probably expected to sign some documents that are being sent automatically, and/or be informed of this direct debit. However the fact that (s)he is only informed by email and that quite late, because it went into his/her spam folder, has several negative consequences (being worried, calling the bank, having to check the spam folder, having to pay more) that could have been avoided if (s)he had been contacted by the bank to inform him/her that the switch had been made. It is clear that had the participant had better control of the situation, there would have been fewer problems. Has free will been properly exercised through this mesh of interconnected automated systems? Or has automation interfered and thwarted conscious direction?

The analysis of the data is thus suggestive of the phenomenon of co-direction identified in Section 2, in instances of participants' feeling a lack of control. For example, the diary entries in Table 3 represent several nuanced aspects of control.

\section{Table 3 Examples of control issues}

I will use the phone throughout the day to speak to my girlfriend and friends while also checking social apps during lunch and breaks and the occasional bit of shopping (Amazon, eBay etc.). (A1-39)

Today I used Instagram a lot as some of my friends are on holiday and they were uploading videos and pictures on their Instagram... however seeing all of these videos from several friends enjoying themselves whilst I was at work made me feel quite down and like I was missing out on things. (A1-31)

There are bits of the old way of doing things I still prefer doing like switching my thermostat on manually rather than having a Hive or a Nest controlling that. Or I prefer using the remote control to switch to a channel instead of asking for Alexa to do that for me. (A3-16)

In the case of A1-39 it should be noted that 'checking' can all too often be read as symptomatic of a 'fear of missing out' (FOMO) [30], a well-known psychological trait of addictive behaviour, and clearly an example of Eyal's 'hooks' at work.

Most importantly however, the analysis revealed a number of examples of feeling overwhelmed by digital experience, as in the case here of A1-31, whose lack of control brings on the depression aspect of FOMO, and in particular A3-16 who prefers to retain conscious control rather than cede simple tasks to a digital assistant. As we move towards DE3 types of events and closer to automated systems such as Hive, Alexa or Nest, A3-16 exhibits a perception that there is a risk 
in surrendering our awareness and control to such systems.

With certain systems such as social networks, then, we may get depressed because we feel we have to check, but checking does us no good. With other automated systems that are based on relieving us from the task of checking such as Hive, Alexa or Nest, we can get worried that it may not be trustworthy and that we will have to control/check it. What is common in these apparently contrasting examples is that when we feel we have to or would have to control/check more than we would normally, we are in fact dissatisfied. This control/checking issue is generated by the digital society.

Conscious control and a lack of control, therefore, are issues our participants are concerned with regarding some types of digital events. Situations in which we direct our technologies to serve us, becoming situations in which new technologies seem to be increasingly co-directing our activities, need to stay short of situations in which our technologies are directing our activities.

\section{Mindfulness}

How then do we counter these problems? Bergson scholar Yasushi Hirai suggests that "In terms of digital events, it might be worth reconsidering the timeefficiency fundamentalism of technology: it risks decreasing the heterogeneity, i.e. thickness, of our various timescales, which is the very ground for our mindful enjoyment of experience." [17] Time, in other words, and the mindfulness with which to experience it, is, in Hirai's reading of Bergson for the $21^{\text {st }}$ century, the very essence of our free will, of our ability to be the rider of the elephant and direct it as we will. Our daily experiences encompass but go beyond digital events and require a general mindfulness. In the context of digital events, then, an 'IT mindfulness' is required.

Brown and Ryan define mindfulness as "The state of being attentive to and aware of what is taking place in the present" [7, p822]. While Thatcher et. al.'s conceptualization of IT mindfulness is clearly that of a trait, Brown and Ryan's conceptualization of mindfulness is that of both a state and a trait. [38, 7, p824]. Both consistent with Weick and Putnam [42] and Brown and Ryan [7], we define IT mindfulness as an open awareness of and attention to current digital experience which may be reflected in a more regular or sustained consciousness of ongoing events, and which allows sufficient time and awareness to make informed choices. Without that time and IT mindfulness - in a fast-paced world of constant digital stimulation - the rider is at risk of being overwhelmed by the elephant, and the elephant driven by the many stimuli around it, not by ourselves.

Mindfulness, in the IS and Organisational literature, has been largely of what Weick and Putnam describe as a Western, conceptual, flavour $[42,22]$. They quote Gunaratana to describe the more Eastern conception: "Mindfulness is very much like what you see with your peripheral vision as opposed to the hard focus of normal or central vision. Yet this moment of soft, unfocussed awareness contains a very deep sort of knowing that is lost as soon as you focus your mind and objectify the object into a thing."[42] This is very redolent of Bergson's intuition philosophique [3, p33], by which the objectification performed by the intellect, looking back on what has passed, can be superseded by a more Gestalt awareness of durée reélle in the now. This is in keeping with the impermanence implicit in the Eastern conception of mindfulness. Gunaratana says, again, "there are really no entities that are unchanging or permanent, only processes." [42]. By the same token, however, the more Western conception of mindfulness, represented principally by the work of Langer, chimes better with Haidt's image of rider and elephant, and the dangers of acting on "automatic pilot." $[42,22]$. As Weick and Putnam conclude, then, there is scope for us to "transcend the constraints of conceptual mindfulness and incorporate Eastern insights" [42]. Process philosophy, we argue, offers just such scope.

Participants in the project spoke of taking time out, through distancing themselves from their digital devices for periods of time, switching off in order to focus on the simpler pleasures of words on paper. They expressed a desire to stay mindful to their experience, and not to the demands of the digital. Interestingly, some of their digital experiences were leading to delusion [42] and fear of being abused (see Table 4).

\section{Table 4 Examples of Mindfulness / Delusion}

Today I browsed on the dating app Tinder too just looking... Hopefully meet someone off it but I never feel that positive about it. The app is not really enjoyable because everyone feels disposable in a way. It's easy to use but there's not much to it. Literally a swip[e] to the left or right. For that reason I don't use the app that much. (A1-31)

I am not into all these Alexas/Nest that is privacy again, Alexa I heard stuff, Alexa listening to you all the time, to your conversations in the house and targeting adverts depending on what you've talked about and I don't want to do that, or Hive knowing what time I'm home, you know, when I am in work and stuff like that. So, what is private? As long as I can control it I will try and do that. (A3-16) 
Clearly, for A1-31, there is both a habitual - hookdriven - behaviour, and a consciousness and resistance to that habitual behaviour, in their relationship with the dating app. For A3-16 the prospect of being listened to by Smart Home assistants is very off-putting. In both these cases the participants express a sense that their digital experiences in some sense dehumanise making people feel 'disposable' or lacking privacy. So, switching off our digital devices from time to time in order to listen to our own elephant rider, we would argue, is an example of the kind of moderation foregrounded by many moral philosophies [16].

In today's world of digital events, then, resistance to the fateful allure that is not only possible but sought by many of the technologies around us becomes key. Reading, exercising and other involvements instead of smartphones, along with the non-adoption of some technologies seen as clearly overstepping certain boundaries, all express concerns about being sufficiently in control of the digital influences in order to be able to put them down, to have 'me time'.

The future does not exist, and the universe is making itself up as it goes along - through our consciousness. These are the primary lessons from process philosophy. The Mindfulness required of us, then, is clearly of existential importance.

\section{Conclusion}

'Infomateriality', we contend, is a notion by which we might understand the true nature of the ubiquitous, always-on computational world information systems have brought about, in which digital events are unfolding at all times, all around us, to us, by us, between us. It may be understood as a condition of human societies in which our exchange of information, and the digital tools with which we undertake that exchange, have become co-constitutive of the physical context in which we live, and are increasingly becoming co-directors of our lives.

The responses from the participants in our project, confronted with the unique synthesis of Bergson and Whitehead's process philosophies and the other lenses we have used for our thematic analysis, as this paper has demonstrated, bear this out.

'Infomateriality' returns individual experience to a centrality of scientific understanding from which it has been wrongly banished, alongside the broader social and material conditions our analyses may explore, in our understanding of what information is, what material reality is, what it is like, and how the enactment of information is constitutive of individuals, societies, and the materiality of the world we inhabit.
The infomaterial is thus a concept for today's "always on" digital world, and enjoins us, as designers and users of information systems, (i) to make room for mindfulness, and (ii) to approach our work as technologists with the strongest ethical principles, cognizant of the co-directional power of the technologies we deploy into people's lives.

\section{References}

[1] H. Bergson, Time and Free Will, George Allen and Unwin, New York, 2005

[2] H. Bergson, Creative Evolution, Random House Modern Library, New York, 1944

[3] H. Bergson, The Creative Mind, Philosophical Library, New York, 1946

[4] V. Braun, and V. Clarke, "Using Thematic Analysis in Psychology", Qualitative Research in Psychology 3(2), 2006, pp. $77-101$

[5] M. Bruckes, J-G. Grotenhermen, F. Cramer, and G. Schewe, "Paving the Way for the Adoption of Autonomous Driving", European Conference on Information Systems (ECIS), Sweden, June 8-14, 2019

[6] C. Bush, and E. Buie, "From darkness to light: Design to evoke the unconscious", in D. Kreps, (ed.) Understanding Digital Events, Routledge, London, 2019

[7] K.W. Brown and R.M. Ryan, "The Benefits of Being Present: Mindfulness and Its Role in Psychological WellBeing", Journal of Personality and Social Psychology, 84(4), 2003, pp. 822-848

[8] P. Checkland, "Information Systems and Systems Thinking: Time to Unite?", International Journal of Information Management, (8) 1988, pp. 239-248

[9] M. Cheikh-Ammar, "The IT artifact and its spirit: a nexus of human values, affordances, symbolic expressions, and IT features", European Journal of Information Systems, 27(3), 2018, pp. 278-294

[10] M. Coeckelbergh, "Technology, Narrative, and Performance in The Social Theatre", in D. Kreps, (ed.) Understanding Digital Events, Routledge. London, 2019

[11] M. Epperson, Quantum Mechanics and the Philosophy of Alfred North Whitehead, Fordham University Press, New York, 2004

[12] N. Eyal, (with R. Hoover) Hooked: How to Build HabitForming Products. Penguin, London, 2014

[13] J. Haidt, The Righteous Mind. Penguin, London, 2012 
[14] T. Harris, "Technology is Downgrading Humanity: Let's Reverse That Trend Now" https://www.tristanharris.com/resources/ 2016

[15] D. Hein, P. Rauschnabel, J. He, L. Richter, and B. Ivens, "What Drives the Adoption of Autonomous Cars?", International Conference on Information Systems, San Francisco, 2018

[16] Hesiod, Works and Days, Penguin, London, 2018

[17] Y. Hirai, "Event and mind: An expanded Bergsonian perspective", in D. Kreps, (ed.) Understanding Digital Events, Routledge, London, 2019

[18] D. Kreps, Against Nature, Routledge, London, 2018

[19] D. Kreps, and K. Kimppa, "Theorising Web 3.0", Information Technology and People, 28(4), 2015, pp. $726-741$

[20] N. Kühl, M. Goutier, R. Hirt, and G. Satzger, "Machine Learning in Artificial Intelligence", Hawaian International Conference on Systems Sciences, Hawaï, 2019

[21] G. Lakoff and M. Johnson, Philosophy in the Flesh, Basic Books, New York, 1999

[22] E. Langer, Mindfulness, Da Capo Press, PA, 1989

[23] E.J. Lowe, A Survey of Metaphysics, Oxford University Press, Oxford, 2009

[24] L. Markus and F. Rowe, "Is It Changing the World? Conceptions of Causality For Information Systems Theorizing", MIS Quarterly, 42(4), 2018, pp. 1255-1280

[25] W. Mays, The Philosophy of Whitehead, George Allen and Unwin, London, 1959

[26] R.C. Mesle, Process-Relational Philosophy, West Templeton Press, Conshohocken, PA, 2008

[27] G.P.Z. Montesdioca, and A.C.G. Macada, "When we need to know everything", European Conference on Information Systems (ECIS), Stockholm \& Uppsala, Sweden, June 8-14, 2019

[28] A.M. Oberländer, M. Röglinger, M. Rosemann, and A. Kees, "Conceptualizing business-to-thing interactions - A sociomaterial perspective on the internet of Things", European Journal of Information Systems, 27(4), 2018, pp. $486-502$

[29] W. Orlikowski, and S. Scott, "The Entangling of Technology and Work in Organizations", LSE Working Paper Series, 168, 2008

[30] A.K. Przybylski, K. Murayama, C.R. DeHaan, and V. Gladwell "Motivational, emotional, and behavioral correlates of fear of missing out", Computers in Human Behavior, 29, 2013, pp. 1841-1848

[31] F. Rowe "Being critical is good, but better with philosophy! From digital transformation and values to the future of IS research", European Journal of Information Systems, 27(3), 2018, pp. 380-393

[32] N.D. Schüll, Addiction by Design: Machine Gambling in Las Vegas, Princeton University Press, Princeton, 2014

[33] D. Skrbina, Panpsychism in the West, MIT Press, Cambridge, MA, 2007

[34] B. Stahl, "Morality, Ethics, and Reflection: A Categorization of Normative IS Research", Journal of the Association for Information Systems, 13(8), 2012

[35] G. Strawson, "Realistic monism: why physicalism entails panpsychism", Journal of Consciousness Studies, 13(10-11), 2006, pp. 3-31

[36] E.B. Swanson, and N.C. Ramiller, "Innovating mindfully with information technology", Management Information Systems Quarterly, 28(4), 2004, pp. 553-583

[37] J.W. Sutherland, "Directive Decision Devices: Reversing the Locus of Authority in Human-Computer Associations", Technological Forecasting and Social Change (75:7), 2008, pp. 1068-1089

[38] J.B. Thatcher, R.T. Wright, H. Sun, T.J. Zagwnczyk and R. Klein, "Mindfulness in information technology use: Definitions, distinctions, and a new measure", Management Information Systems Quarterly, 42(3), 2018, pp. 831-847

[39] O. Turel, C. Matt, M. Trenz, C.M.K. Cheung, J. D'Arcy, H. Qahri-Saremi, and M. Tarafdar, "Panel Report: The Dark Side of the Digitization of the Individual", Internet Research, 2019, 29(2), pp. 274-288

[40] I. Vaghefi, and L. Lapointe "An Examination of Craving for Social Networks", Americas Conference on Information Systems (AMCIS), San Diego, CA, 2016

[41] I. Vaghefi, L. Lapointe, and C. Boudreau-Pinsonneault, "A typology of user liability to IT addiction", Information Systems Journal, 27(2), 2017, pp. 125-169

[42] K.E. Weick and T. Putnam, "Organizing for Mindfulness Eastern Wisdom and Western Knowledge", Journal of Management Inquiry, 15(3), 2006, pp. 275-287

[43] A.N. Whitehead, Science and the Modern World, The Free Press Toronto, 1932

[44] A.N. Whitehead, The Concept of Nature, Cosimo, New York, 2007

[45] A.N. Whitehead, Modes of Thought, The Free Press Toronto, 1938 